\title{
11. GEOTHERMAL MEASUREMENTS, LEG 21
}

\author{
R. P. Von Herzen, Woods Hole Oceanographic Institution, Woods Hole, Massachusetts
}

\section{INTRODUCTION}

Several thousand measurements of oceanic heat flow have accumulated since measurement techniques from oceanographic vessels were developed about 20 years ago. One of the persistent characteristics of the oceanic values is the large variability, particularly in tectonic regions (Lee, 1970). Much of this variability may result from local or regional environmental effects (topography of the sea floor, irregular distribution of sediment and rock, etc.), variations in heat transfer mechanisms (localized conduction and convection anomalies), or time-dependent phenomena at the sea floor (sedimentation rates, bottom water temperature, etc). The data obtained from standard oceanographic observations can seldom resolve which of these are the most significant sources of variability or the magnitude of possible bias in the values measured. Obviously, it is important to identify these effects and, if present, to obtain regional values of heat flow.

Deep Sea Drilling Project offers the opportunity to extend thermal measurements to much greater (1 to 2 orders of magnitude) depths below bottom than are possible with the oceanographic techniques. Detailed measurements to depths of several hundred meters have the potential to resolve many of these uncertainties and produce heat flow values which are much more accurate. Measurements with a logging cable have already been reported for Leg 5 (Burns, 1970) and Leg 8 (Von Herzen et al., 1971) of this project. Self-contained instrumentation has now been developed and successfully utilized on Leg 19; the instrumentation and measurements are described by Erickson (1973). The present report describes the measurements obtained in the Melanesian region (SW Pacific) on DSDP Leg 21.

\section{TEMPERATURE DATA}

Although downhole temperature measurements were attempted at all sites except one (Site 203) on Leg 21, only at four sites were suitable in situ temperature data obtained. The lack of appropriate data at other sites was attributable for the most part to premature unlatching of the instrumentation, causing the instrument to be damaged by physical shock against the upper end of the inner core barrel, or nonpenetration of in situ sediment. This mode of failure was attributed to the effect of the flapper valve located at the bottom of the drill string, designed to prevent back-flow of fluids. One effect of this valve is to lower the fluid level in the drill string by many tens of meters as a result of withdrawal of the line and core barrel, indirectly causing release of the heat-flow instrument latch on impact with the water level surface after free fall of the core barrel through this distance. The direct effect of the valve is to release the instrument latch by impact of the probe with the flapper valve when the core barrel reached the bottom of the drill pipe, prematurely forcing the instrument inside the core barrel, if it is not already there due to impact after core barrel release. Both cases are believed to have occurred repeatedly on Leg 21 measurement attempts, the former being the most catastrophic (usually loss of data and damage to instrument).

Of the fourteen downhole attempts in which at least some data were successfully acquired, the temperature-time records combined with a log of the operations were usually sufficient to determine whether in situ sediment temperatures were measured. For example, Figure 1 illustrates an apparently successful measurement in which relatively steady temperatures were achieved within $1 / 2$ minute after penetration at the bottom of the hole. A similar and perhaps more typical record is presented in Figure 2. In this case, the rapid rise of temperature is followed by a much slower decay which continues uninterrupted except for a small disturbance on commencement of coring. It can be shown (Appendix) that this thermal decay has a time constant appropriate for the conduction of heat from the core barrel jacket to the probe surrounded by a cored annulus of sediments. Such records are interpreted as cooling of the probe and surrounding sediment core after both have been forced up into the core barrel by super-penetration of the drill string. By comparison with Figure 1, in which the probe probably remained outside of the core barrel during the measurement, the in situ temperature for measurements on which super-penetration occurs is probably close to the maximum recorded.

A record which shows little temperature change at the time of expected probe penetration (Figure 3) suggests that the instrumentation has prematurely entered the core barrel before penetrating the sediments. Occasionally a sharp temperature rise is recorded at commencement of coring (Figure 4), after the probe has apparently penetrated the sediments entering the core barrel by the force of the instrumentation weight. This type of recording emphasizes the requirement for correlation of time on the recording instrument with significant events in the drilling operations.

In situ temperatures were apparently measured for eight downhole attempts at four sites on Leg 21. The temperature-time records obtained for each successful measurement, in addition to those already discussed above, are presented in Figures 5 through 9.

Table 1 summarizes the successful geothermal measurements for Leg 21. At each site, the depth below bottom is taken from the drillers' logs of the amount of drill pipe extending below bottom. The uncertainty in relative depth of the temperature measurements may depend on the events associated with each measurement as discussed below, but has been estimated at \pm 1 meter for each 


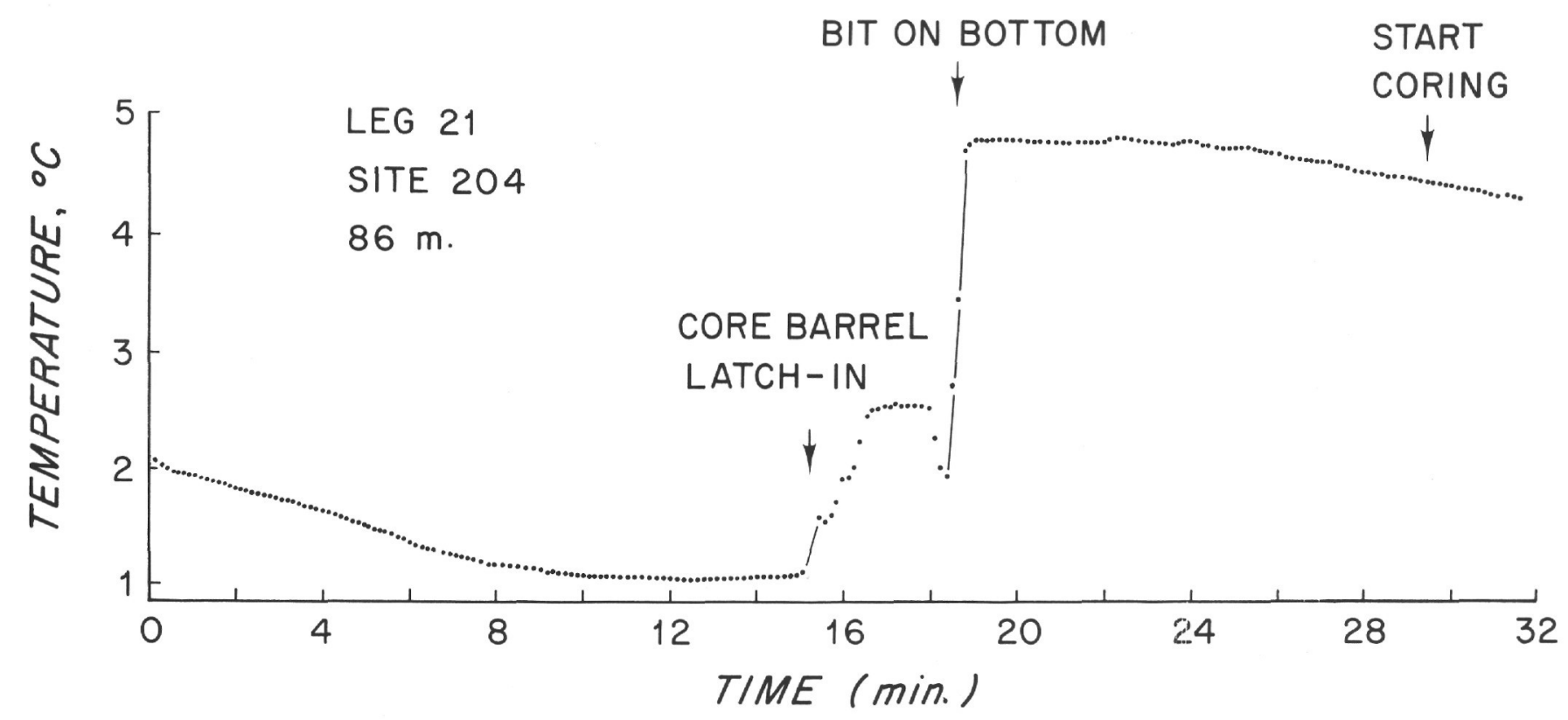

Figure 1. Temperature versus time (relative) record at Site 204, 86 meters depth. Data points normally spaced at 8.0-sec intervals, connected by thin lines where appropriate to illustrate continuity. Significant operational events noted by arrows.

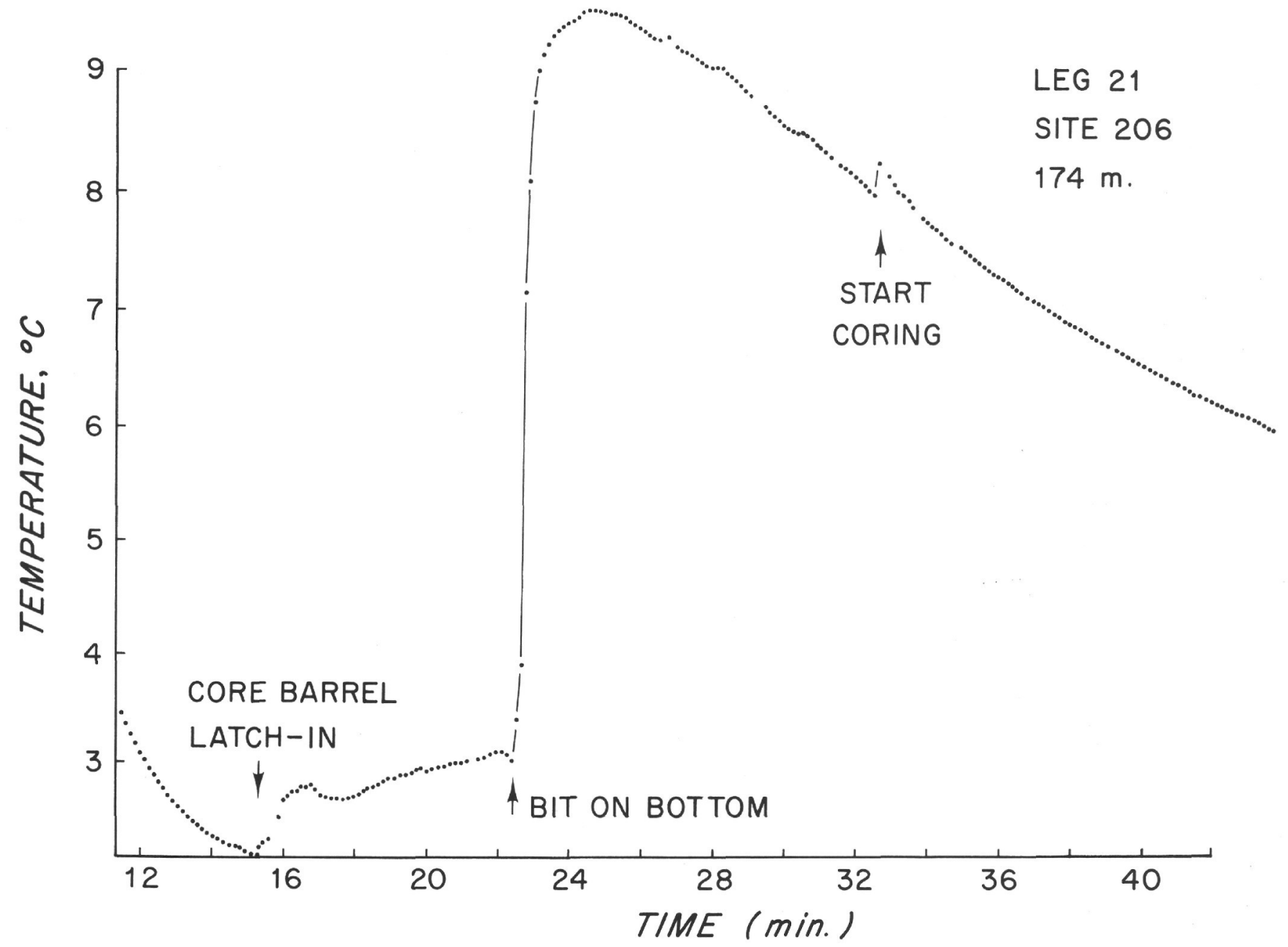

Figure 2. Site 206, 174 meters depth. See Figure 1 caption for details. 


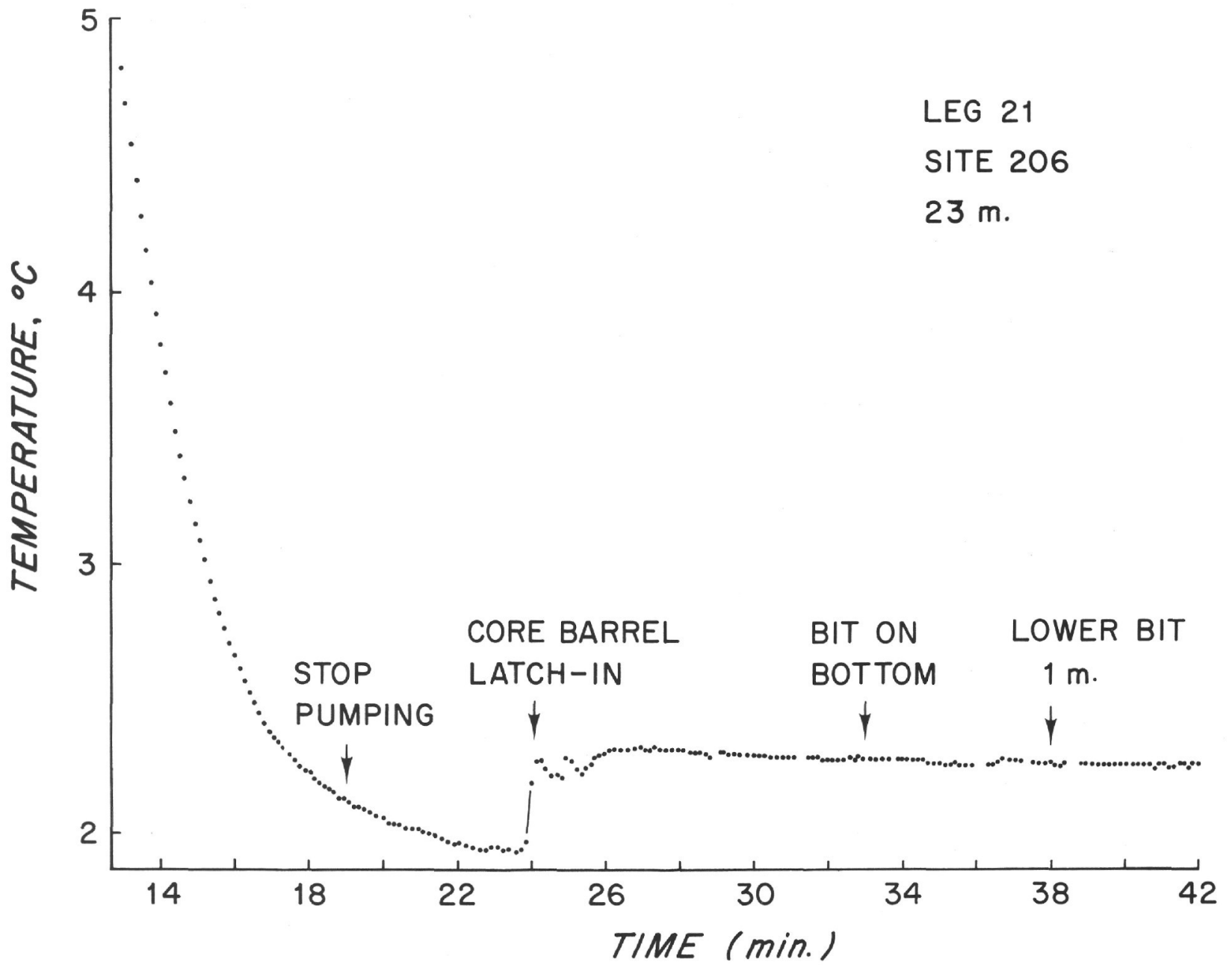

Figure 3. Site 206, 23 meters depth. See Figure 1 caption for details.

measurement. The "zero" depth measurement at each site has a similar uncertainty due to the inability to "feel" the water-sediment interface with the heavy drill pipe.

Except at Site 209, the temperature values at "zero" depth are obtained from the downhole instrument during its slow passage through the drill string above the sea floor. These depth uncertainties have been combined with the uncertainties in temperature values to give the gradient uncertainties listed in Table 1 . In the following paragraphs, I discuss the successful temperature measurements and gradients deduced at each site.

Site 204. The single successful measurement at this site, at a depth of 86 meters below bottom, has already been described among the examples given above (Figure 1). The relatively steady portion of the record is interpreted as the in situ temperature, $4.79^{\circ} \mathrm{C}$. Because of the relatively great water depth at this site, it is probable that the steady temperature of $1.06 \pm 0.02^{\circ} \mathrm{C}$. recorded during passage of the instrument through the drill string, is close to the bottom water temperature. This is confirmed $\left( \pm 0.3^{\circ} \mathrm{C}\right)$ by hydrographic stations occurring within several hundred kilometers of the site (provided by National Oceanographic Data Center, Washington, D.C., 1972). The bottom water temperature and that measured at 86 meters below bottom

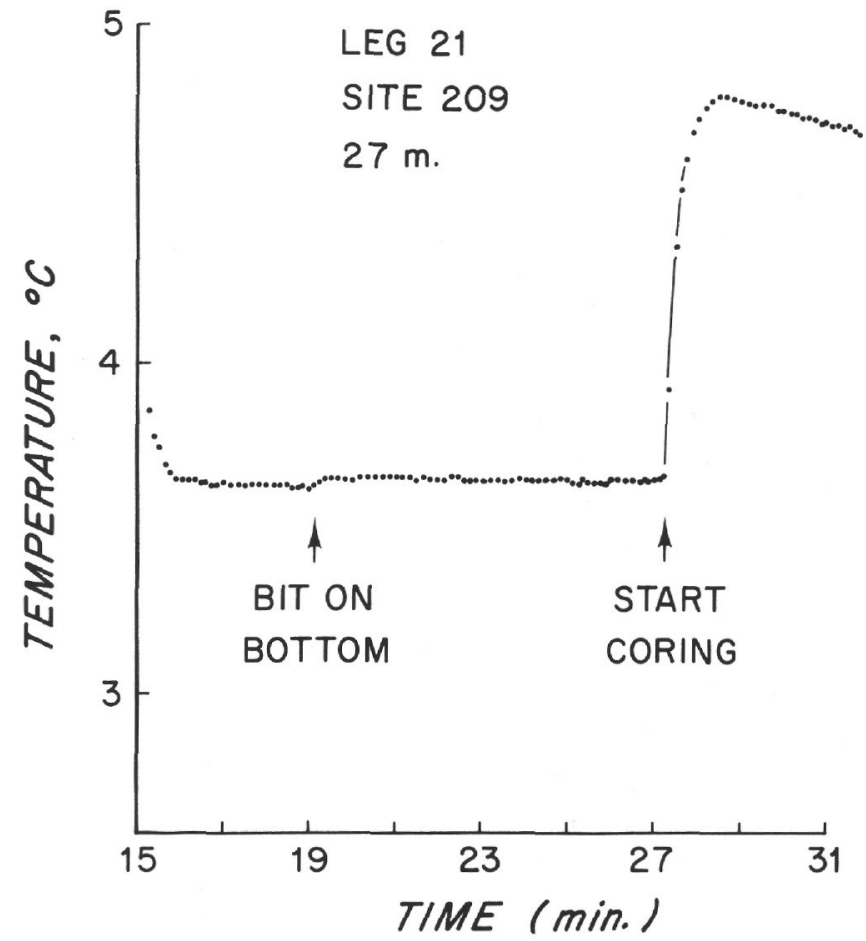

Figure 4. Site 209, 27 meters depth. See Figure 1 caption for details. 


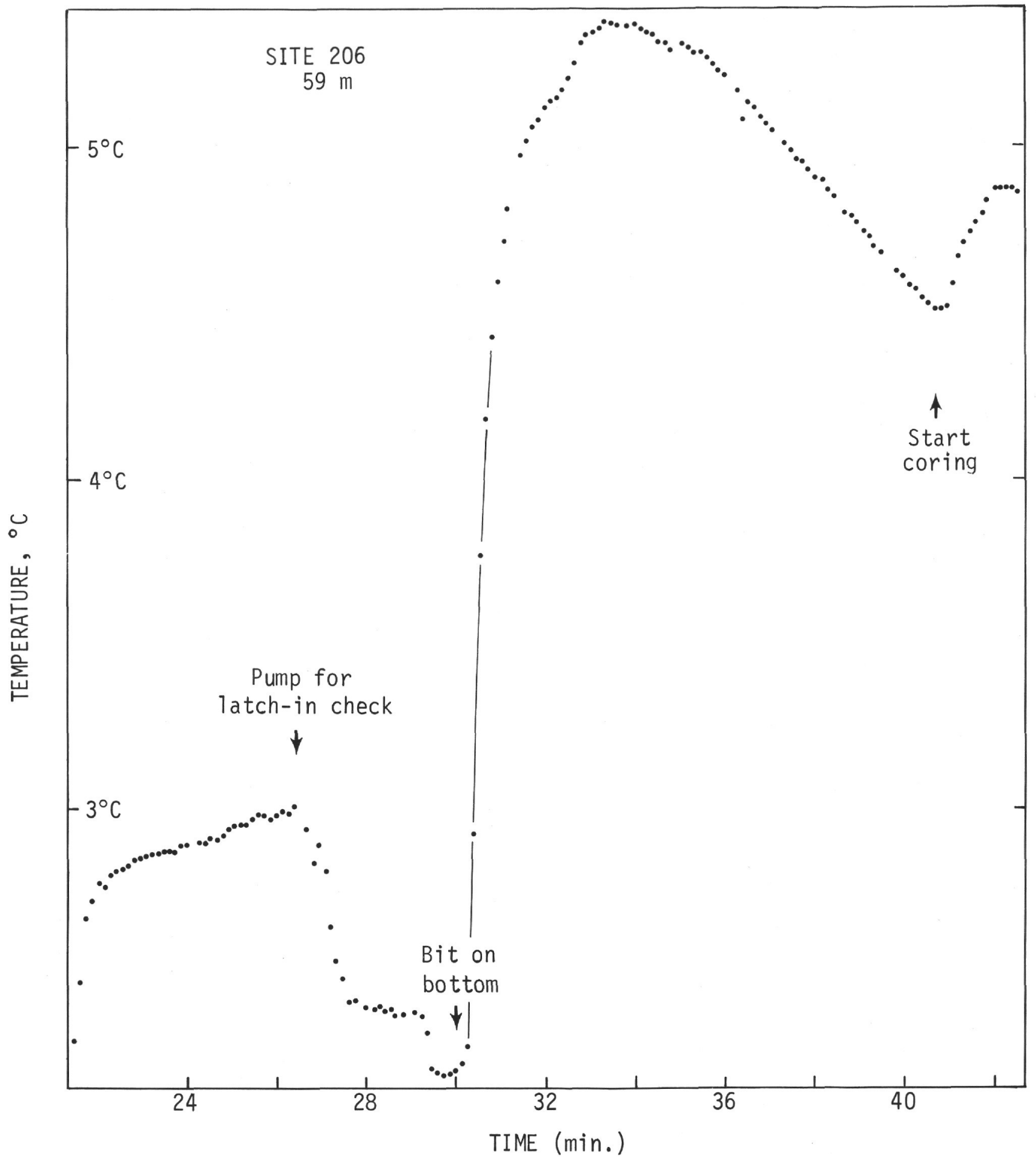

Figure 5. Site 206, 59 meters depth. See Figure 1 caption for details.

combine to give a gradient of $4.3 \times 10^{-} 3^{\circ} \mathrm{C} / \mathrm{cm}$ over this depth interval (Figure 10).

Site 206. A total of four apparently successful measurements to depths slightly exceeding 300 meters make this site the most extensively measured for in situ temperatures of the Leg 21 sites. The measurement at 59 meters depth (Figure 5) showed a rapid, although slightly disturbed, rise to a maximum temperature of $5.34^{\circ} \mathrm{C}$. The subsequent temperature decay was slower and only slightly disturbed until commencement of coring, which produced another increase. The slow cooling is probably produced by radial conduction of heat after the probe and penetrated sediments have been pushed up into the core barrel, as discussed above.

Similar records were obtained at depths of 143 meters and 174 meters (Figures 6 and 2, respectively). The rapid increases after probe penetration to maximum temperatures are followed by slow and relative undisturbed thermal 


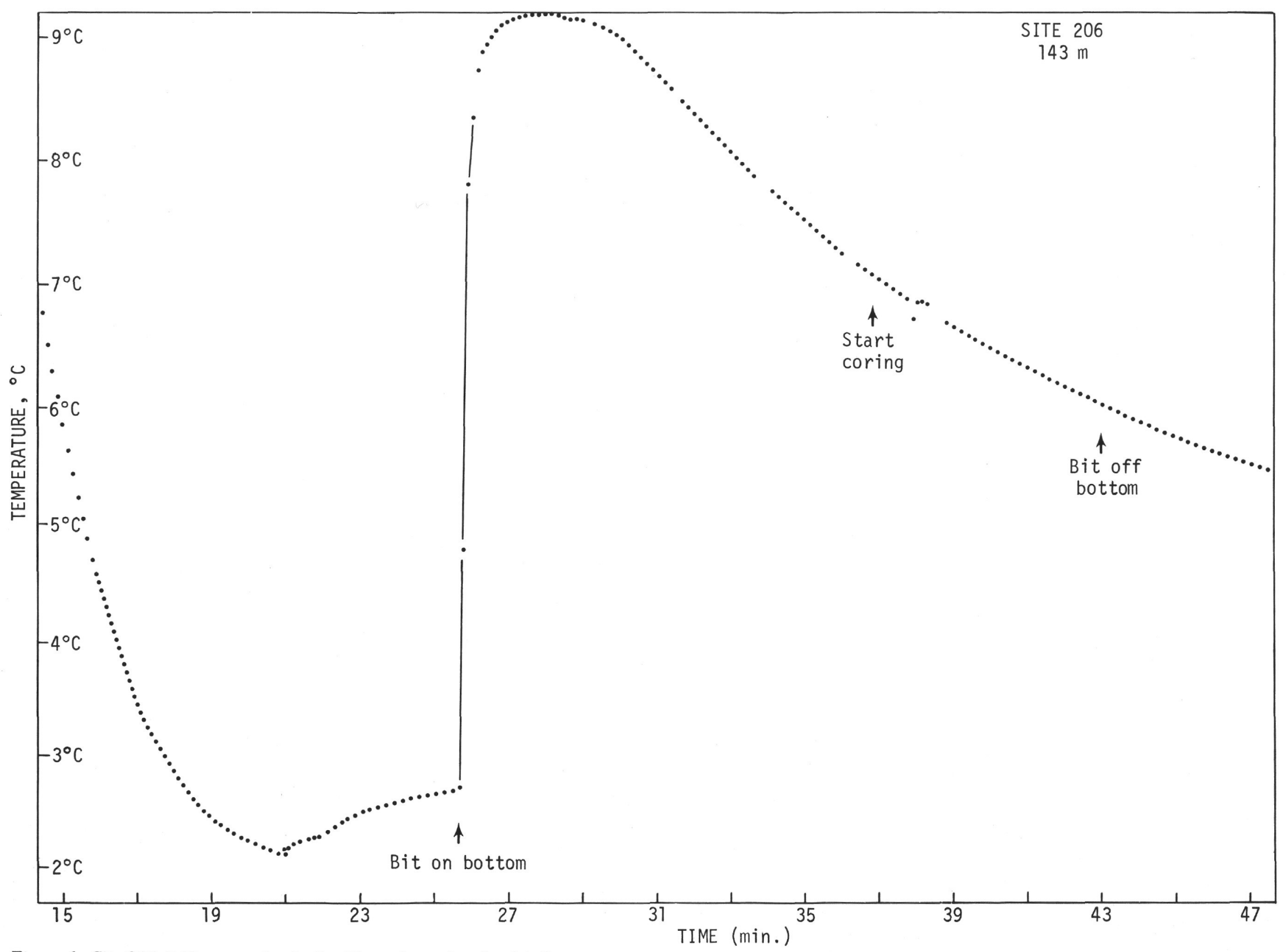

Figure 6. Site 206, 143 meters depth. See Figure 1 caption for details. 


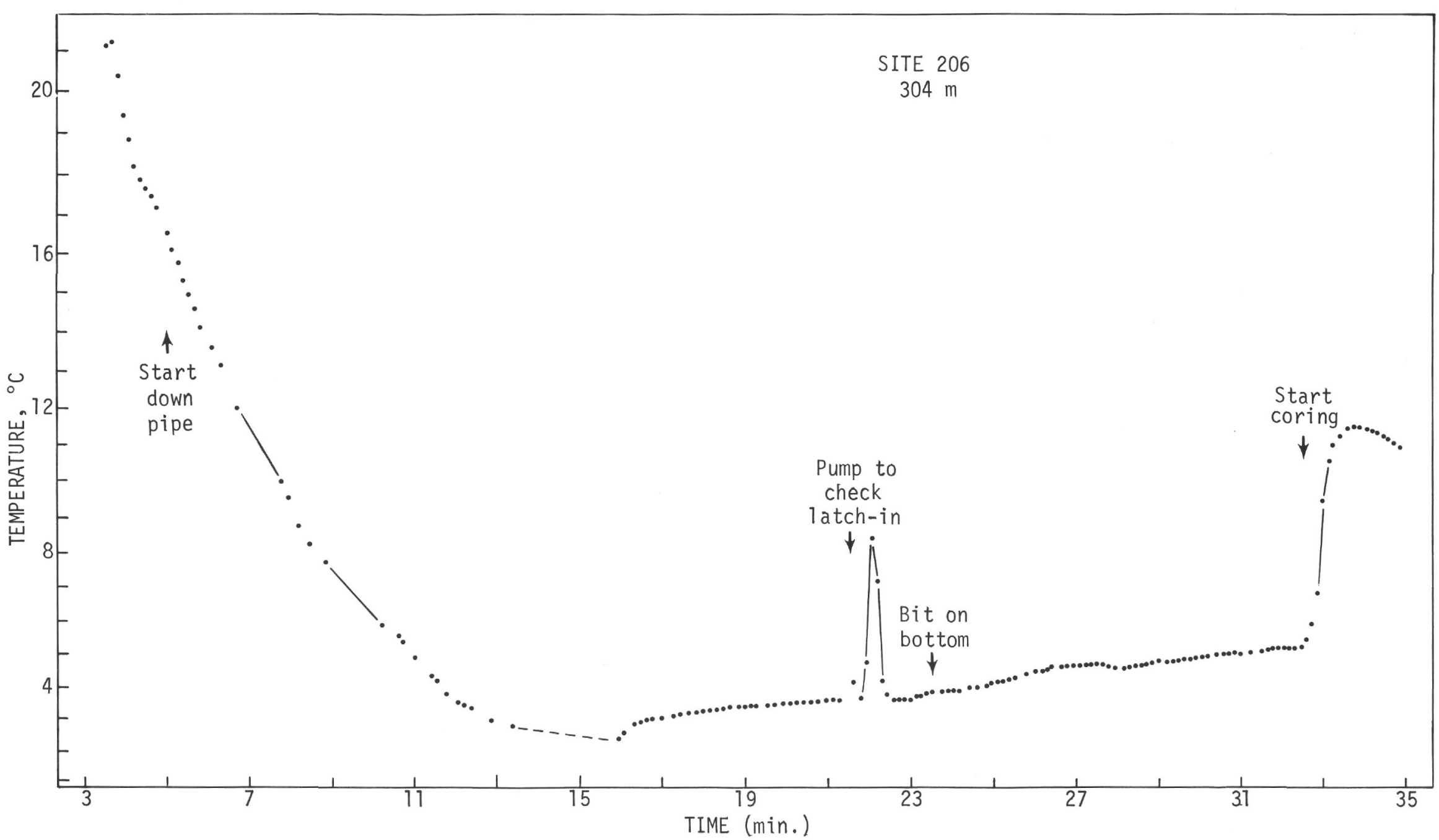

Figure 7. Site 206, 304 meters depth. See Figure 1 caption for details. 


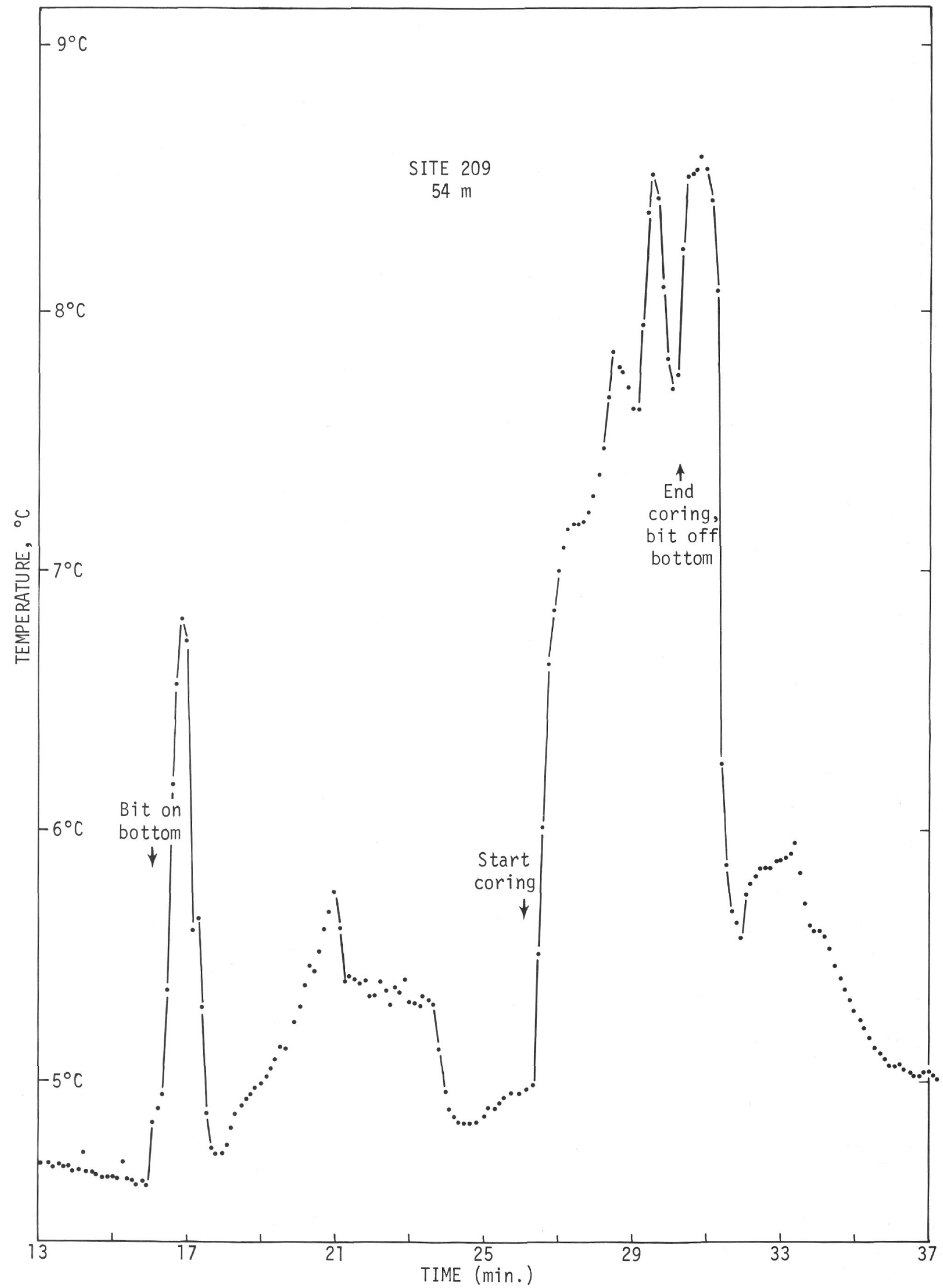

Figure 8. Site 209, 54 meters depth. See Figure 1 caption for details. 


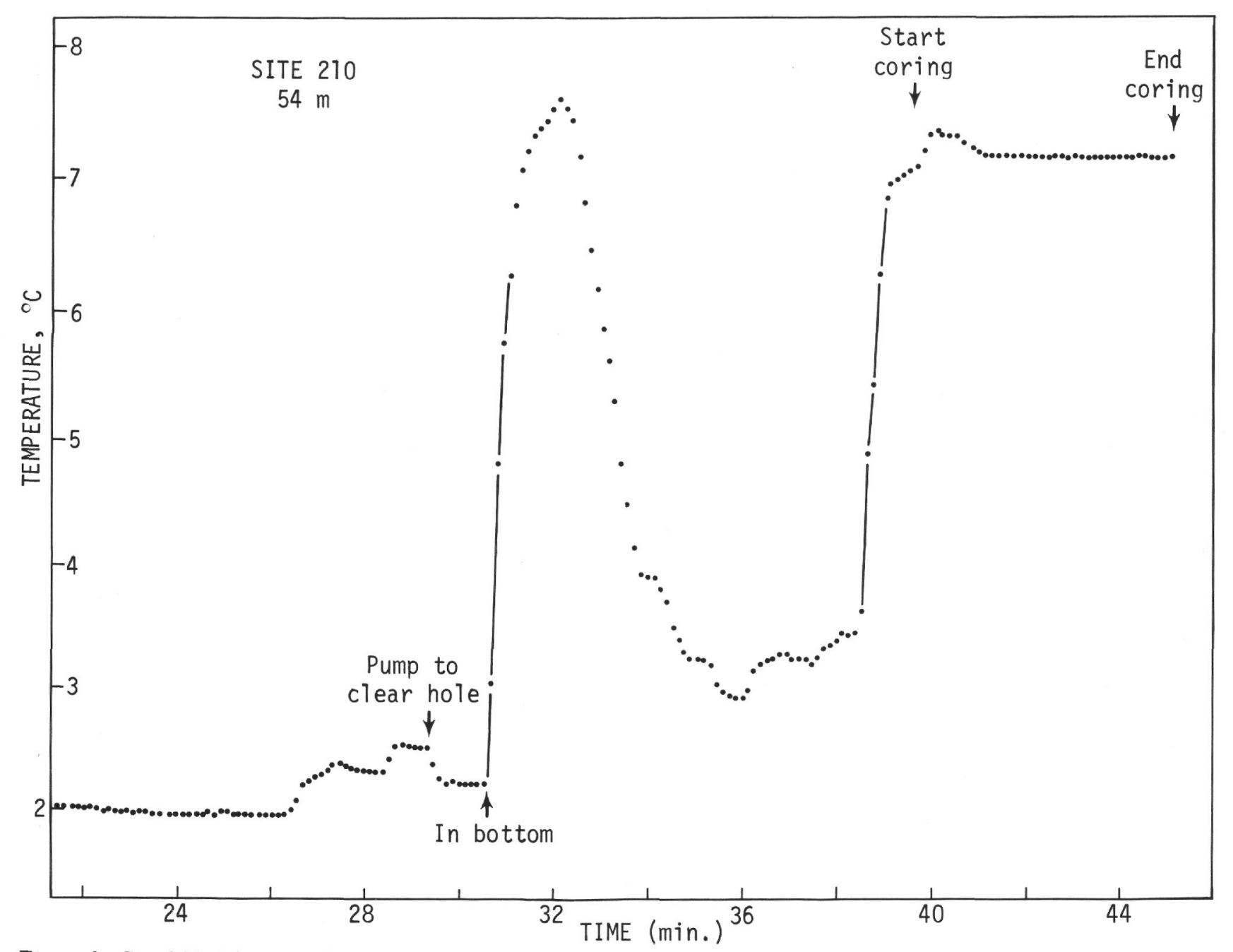

Figure 9. Site 210, 54 meters depth. See Figure 1 caption for aeralls.

decay curves, even after commencement of coring. The maximum temperatures are again believed most representative of in situ values, respectively 9.15 and $9.45^{\circ} \mathrm{C}$.

On the measurement at 304 meters depth (Figure 7), no marked change in temperature occurred at the moment of attempted penetration, only a slow, irregular increase. A marked increase to a maximum of $11.59^{\circ} \mathrm{C}$ occurs after commencement of coring, near the end of the record. Due to the relatively indurated sediments, however, the representativeness of this maximum for the in situ temperature is less certain than for the other measurements at this site.

The temperature gradient determined from these measurements at this site (Figure 11) markedly decreases with depth, particularly below measurement $8(143 \mathrm{~m})$. With a bottom water temperature of $1.98^{\circ} \mathrm{C}$ (Table 1), the gradient between 0 to 59 meters depth is $5.7 \times 10^{-} 3^{\circ} \mathrm{C} / \mathrm{cm}$; below 143 meters, its average value is less than half that at the surface. The low gradient is determined by three temperature-depth points. Unfortunately, the lowest value has considerable uncertainty as discussed above; however, it is consistent with the values at 143 and 174 meters and gives additional evidence for the low gradient determined from these measurements.

Site 209. Two downhole measurements of somewhat doubtful quality comprise the data at this site. Although the quality of data is below that desired, the two measurements probably give minimum values which are self-consistent and commensurate with data from nearby Site 210 . The measurement at 27 meters (Figure 4) shows only a very small rise in temperature at the time of expected penetration, indicating that the instrumentation had entered the core barrel prematurely. However, a large temperature rise and smooth decay followed the commencement of coring. The maximum temperature measured, $4.84^{\circ} \mathrm{C}$, is assumed to be the in situ value.

The measurement at 54 meters (Figure 8) showed a highly variable temperature record through the penetration and coring operations. The temperature increased rapidly to about $6.8^{\circ} \mathrm{C}$ following penetration, but declined equally rapidly after reaching the maximum, suggesting that the probe was released up the core barrel before thermal equilibrium was reached. Similarly, the temperature 
TABLE 1

Geothermal Data, Leg 21

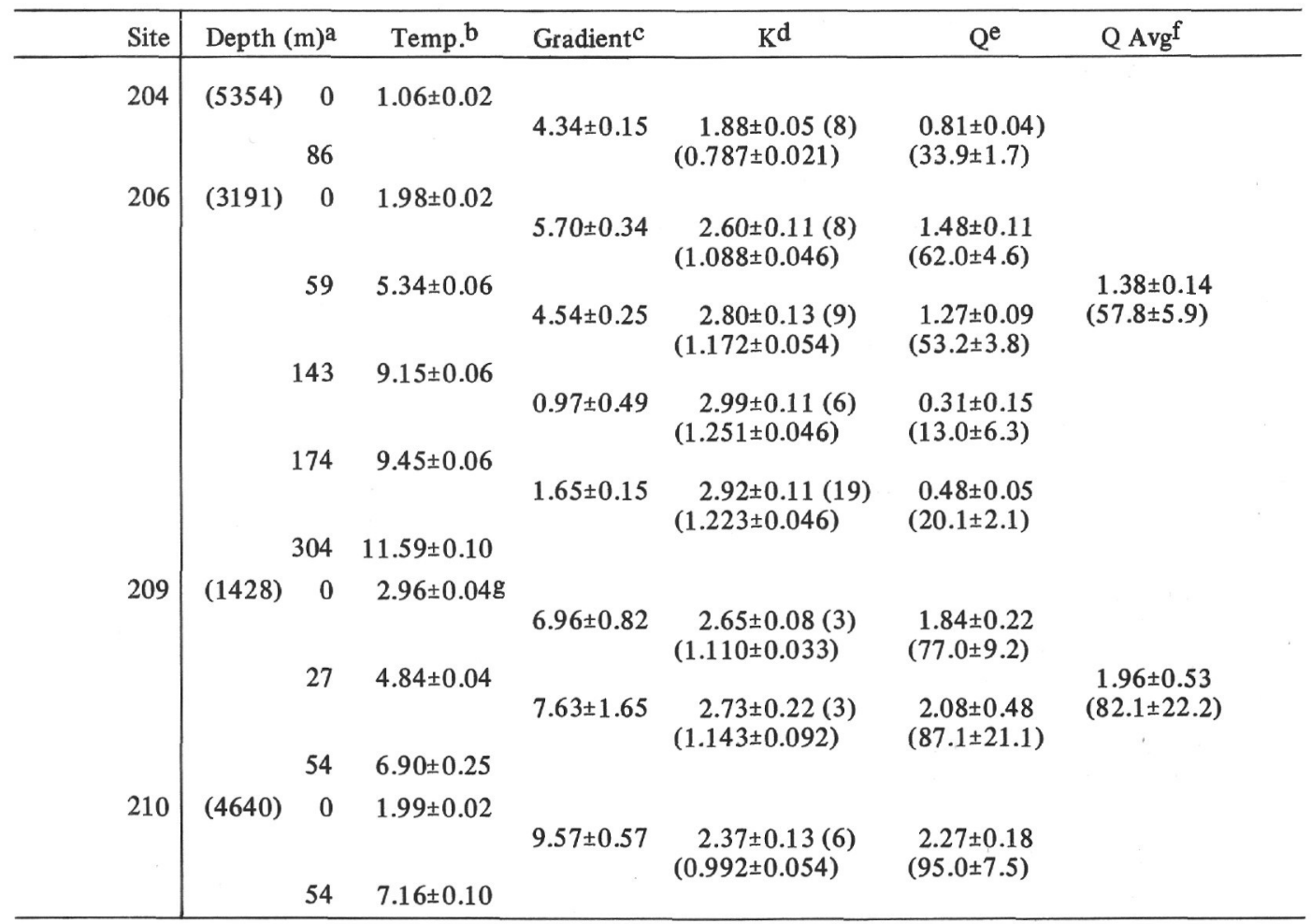

aWater depth in parentheses, taken from echo sounding or drill pipe length at site. Other numbers are depth below bottom.

bSee text for estimated uncertainty in temperature measurements.

${ }^{\mathrm{C}}$ Temperature gradient in $10^{-3^{\circ}} \mathrm{C} / \mathrm{cm} \pm$ estimated uncertainty (see text).

$\mathrm{d}_{\mathrm{K}}=$ thermal conductivity, in $\mathrm{mcal}{ }^{\circ} \mathrm{C}^{-1} \mathrm{~cm}^{-1} \mathrm{sec}^{-1}\left(\mathrm{Wm}^{-1}{ }^{\circ} \mathrm{C}^{-1}\right)$ - Uncertainty ( \pm ) estimated from standard error of values within interval (number in parentheses) $\pm 2 \%$ possible systematic error.

$\mathrm{e}_{\mathrm{Q}}=$ heat flow, in $\mu \mathrm{cal} \mathrm{cm}^{-2} \mathrm{sec}^{-1}\left(\mathrm{mWm}^{-2}\right)$. Uncertainty ( \pm ) computed as RMS sum of uncertainties in gradient and $\mathrm{K}$.

$f_{Q}$ Av at Sites 206 and 209 calculated as average of interval values enclosed by parenthesis. Error ( \pm ) calculated as RMS sum of interval Q error.

increased rapidly after commencement of coring, reaching a plateau somewhat greater than $7^{\circ} \mathrm{C}$ for about $30 \mathrm{sec}$, then became quite variable again. From these data, the in situ temperature is estimated at $6.9 \pm 0.25^{\circ} \mathrm{C}$ at this depth $(54$ $\mathrm{m})$.

The bottom water temperature at this site was not determined by any of the recordings durings traverse of the drill pipe, but was indirectly estimated at slightly below $3^{\circ} \mathrm{C}$ from nearby hydrographic data (National Oceanographic Data Center, Washington, D.C. 1972) ${ }^{1}$. The computed gradient increases somewhat with depth, from $7.0 \mathrm{X}$

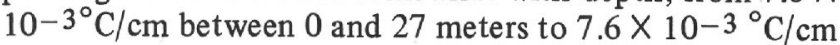
between 27 and 54 meters (Figure 12a).

Site 210. Only one successful downhole measurement (Figure 9) was obtained at this site, at a subbottom depth of 54 meters. The record showed an increase to greater than $7.5^{\circ} \mathrm{C}$ on penetration, but a sharp drop within one minute indicated that the probe was disturbed before reaching equilibrium. After commencement of coring, a relatively steady temperature of $7.16^{\circ} \mathrm{C}$ was recorded for several minutes. This value, combined with the bottom water temperature of $1.99^{\circ} \mathrm{C}$ measured during transit through the drill pipe, gives a gradient of $9.6 \times 10^{-} 3^{\circ} \mathrm{C} / \mathrm{cm}$ to 54 meters depth (Figure 12b).

\section{THERMAL CONDUCTIVITY}

More than 200 measurements of thermal conductivity by the needle-probe method were made on all sites of Leg 21 . The values are listed in the physical properties chapter this volume. For purposes of heat-flow measurements, we have utilized only those measurements which were made on cores recovered down to the depth of the deepest temperature measurement at each site.

These values have been corrected for ambient temperature and pressure conditions following Ratcliffe (1960). The temperature correction is $1 \%$ per $4^{\circ} \mathrm{C}$ difference between the ambient core temperature before the measurement and the in situ core temperature as interpolated between in situ temperature measurements at each site 


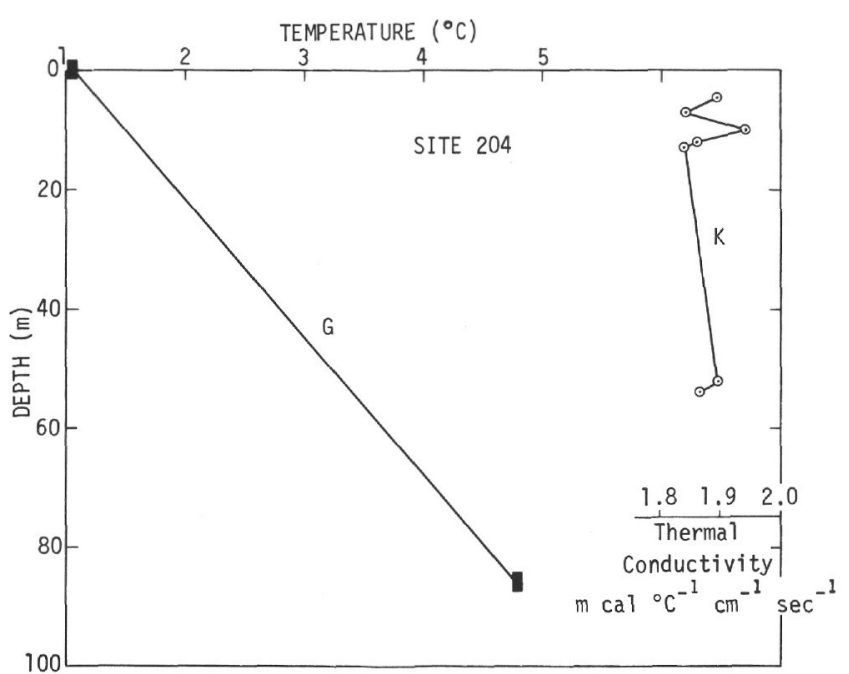

Figure 10. Temperature, temperature gradient $(G)$, and thermal conductivity (K) versus depth at Site 204. Uncertainties in temperature and depth (Table 1, and see text) shown as rectangular symbol at each temperature point. Thermal conductivity values corrected for in situ temperature and pressure (see text).

(Figures 10,11, and 12). The hydrostatic pressure correction is $1 \%$ for each 183 bars (equivalent to 1000 fathoms water depth) of ambient in situ pressure. The in situ pressure is calculated from the water depth, depth below bottom, and density of the sediments (see physical properties chapter, this volume). The total correction is of the order of several percent and is usually dominated by the temperature effect.

The average thermal conductivity for each temperature measurement interval is computed as

$$
K_{\text {avg }}=\left(\frac{1}{n} \sum_{i=1}^{n} \frac{1}{K_{i}}\right)^{-1}
$$

where $n$ is the number of measurements. These are the values given in Table 1 .

\section{HEAT FLOW}

The heat-flow values over each temperature interval (Table 1) were simply computed as the corresponding products of temperature gradient and thermal conductivity. Estimated errors derive from the RMS error estimated for gradient and thermal conductivity, as they are independently measured quantities.

\section{DISCUSSION}

The interval heat flows measured at Leg 21 sites range between 0.31 to $2.27 \mathrm{HFU}$ (Table 1). These extremes are,

\footnotetext{
${ }^{1}$ From data obtained with oceanographic heat-flow apparatus, Langseth et al. (1971) suggest bottom water temperatures of $3.1^{\circ} \mathrm{C}$, about $0.1^{\circ} \mathrm{C}$ higher than that given by Table 1 . Langseth et al. also list water temperatures which are also about $0.1^{\circ} \mathrm{C}$ higher than that measured at Site 210 , or inferred from nearby hydrographic data, at comparable depths. For this reason, I have utilized the hydrographic data near Site 209 for bottom water temperature.
}

respectively, quite low and moderately high compared to previously measured marine heat flow values. Table 1 shows values which vary substantially, and perhaps systematically, among different intervals at some sites (especially Site 206) as well as between sites. For this reason, it is not possible to make firm conclusions about heat flow in the Melanesian region from the Leg 21 data. Nevertheless, it seems probable, for example, that the heat flow at Sites 209 and 210 is significantly higher than that at Sites 204 or 206. We shall return to this comparison later in the discussion.

The large differences in interval heat flows at Site 206 may be explained in different ways. As discussed above, they may simply result from temperature measurements which are not in situ; there is no adequate way to establish this possibility. On the other hand, several geophysical explanations may be considered under the assumption that the temperature measurements represent in situ conditions.

\section{Internal Heating Of A Surface Layer}

The decrease of heat flow with depth suggested by the temperature data at Site 206 might be ascribed to internal heat being generated in the sediments. If the difference in heat flow at the surface of this site (1.5 HFU) and that at 174 meters (or $304 \mathrm{~m})(0.5 \mathrm{HFU})$ results from such an effect, the average heat generation is easily calculated. It is $0.57 \times 10^{-10} \mathrm{cal} / \mathrm{cm}^{3} \mathrm{sec}$ for a layer 174 meters thick, or $0.33 \times 10^{-10} \mathrm{cal} / \mathrm{cm}^{3} \mathrm{sec}$ for a 300 -meter-thick layer.

Possible sources of heat within a sedimentary layer may be the radioactive decay of uranium, thorium or potassium, or the oxidation of organic material (Bullard et al., 1956). Regarding heating by radioactive decay, the rates given above are at least an order of magnitude larger than those for average granitic rocks (Clark, 1966, chap. 24), which are not approached by calcareous sediments. Similarly, the uniformly light-colored calcium carbonate sediments recovered at this site obviously do not contain any large quantity of organic carbon.

We therefore cannot account for any significant sources of heat within the sediments. Also, we note that the measured temperature gradient at this site has its maximum change at about 174 meters depth. A layer with uniform heat generation would show a uniform change of gradient with depth $\left(\partial^{2} \mathrm{~T} / \partial \mathrm{Z}^{2}=\right.$ constant $)$ if thermal conductivity is uniform. There is no evidence of a change in thermal conductivity near this depth. The gradient changes at Site 206 are not easily explained by heat sources within the sedimentary section.

\section{Upward Percolation of Interstitial Water}

The temperature gradient at Site 206 might be associated with flow of interstitial waters. One possibility for fluid flow is the self-compression of porous sediments by the increasing overburden; the general increase of thermal conductivity and bulk density with depth in the cores (see Physical Properties, Site 206), is probably evidence of such effects. Nevertheless, approximate models for numerical computations show that the effect is quite small (Lubimova et al., 1965; Langseth et al., 1966). Upward velocities of the order of millimeters to a few centimeters per year are required to produce significant effects, which exceeds the measured rates of sedimentation 


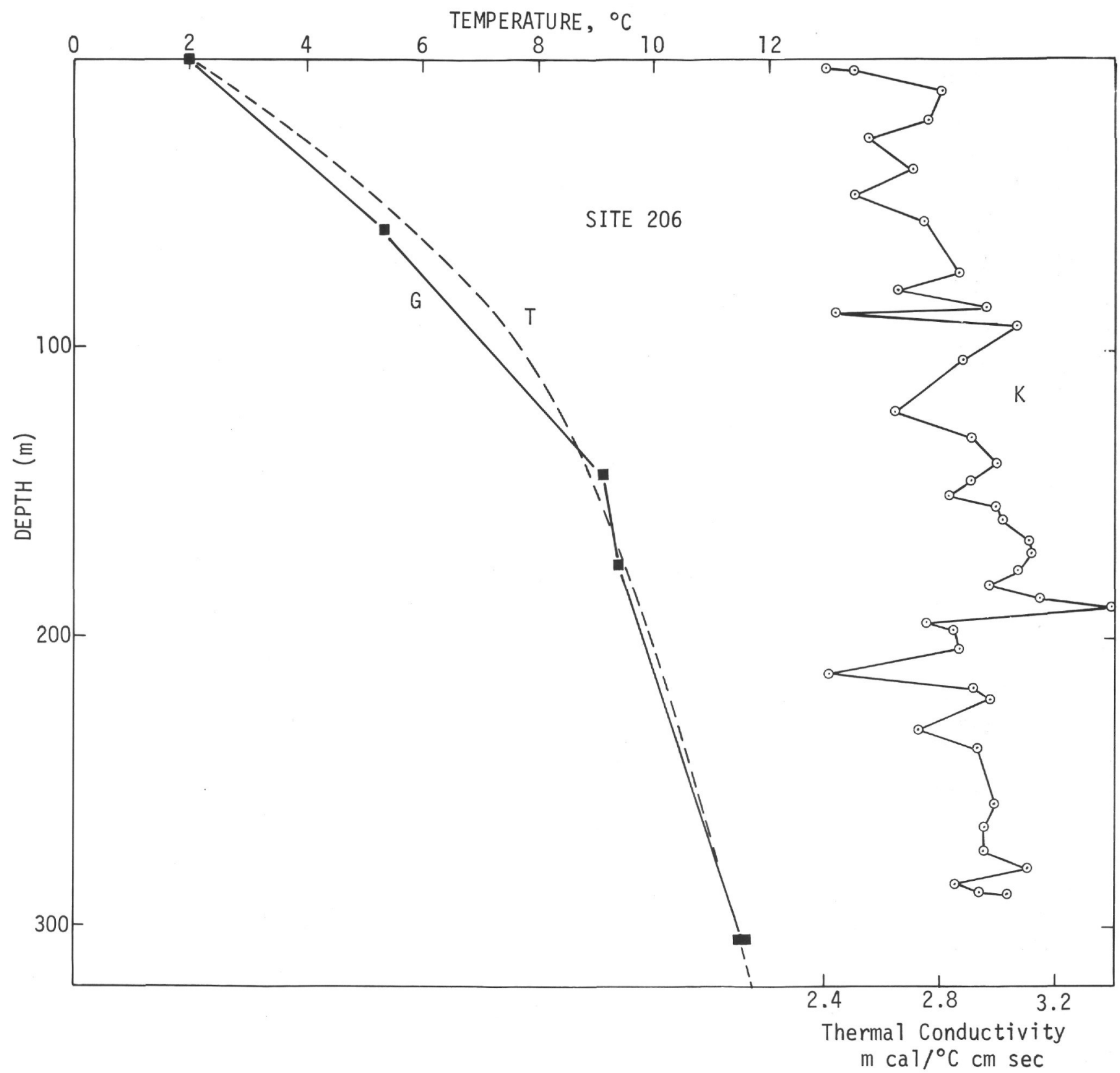

Figure 11. Temperature, temperature gradient $(G)$, and thermal conductivity $(K)$ versus depth at Site 206. Dashed curve $(T)$ is theoretical fit (see text). Symbols same as for Figure 10.

by two or three orders of magnitude. Moreover, even if the rate of sedimentation by two or three orders of magnitude. Moreover, even if the rate of sedimentation were much higher, it can be shown (Langseth et al., 1966) that the suppression of the temperature gradient by rapid sedimentation (Von Herzen and Uyeda, 1963) would always dominate over the enhancement of the gradient by the upward movement of interstitial water.

Fluid flow in porous sediments may also be driven by the buoyancy force established by the vertical temperature gradient. In this case, the flow is similar to convective motions driven by the heating of a fluid from beneath. Lapwood (1948) has treated the problem theoretically for several types of boundary conditions. The onset of convection has been shown to occur for a range of permeabilities and thicknesses of the porous layer (Lapwood, 1948, Table 1). Permeabilities of ocean sediments are usually quite small, on the order of 10-4 Darcy or less (Lister, 1972, appendix I; after data from Hamilton, 1964). Using the scaling formulas of Lapwood, convection could not occur in a layer of such permeability unless the layer thicknesses and/or the temperature gradient were extremely large. Neither of these limits are approached at any of the Leg 21 sites, making the possibility that convection within the sediments has disturbed the temperature gradients seem remote. 


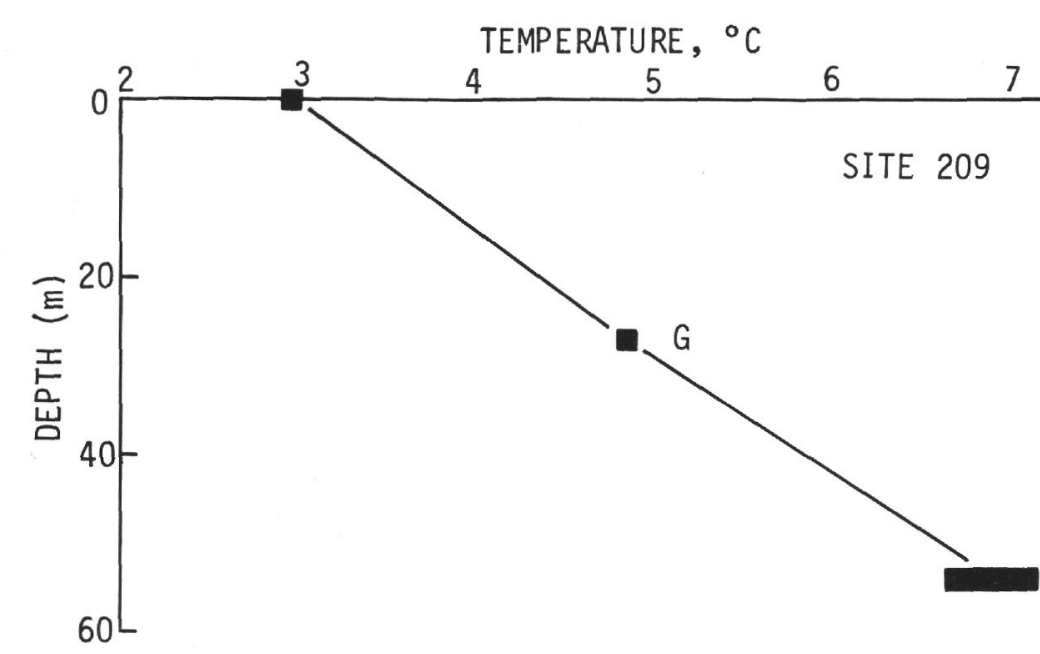

Fig. 12 a

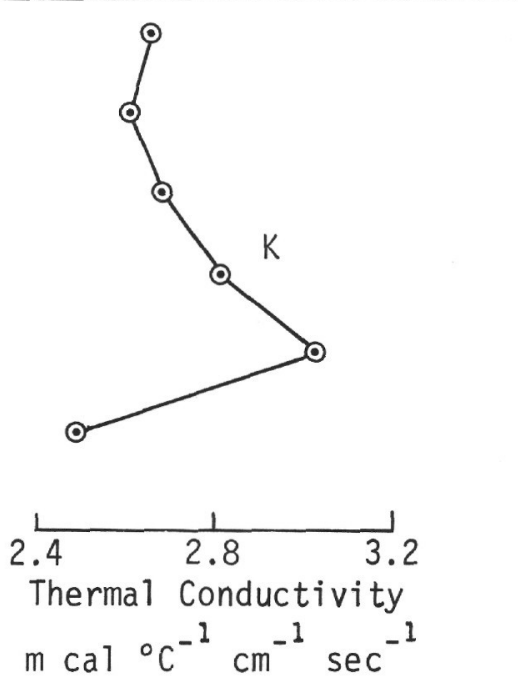

Fig. $12 b$

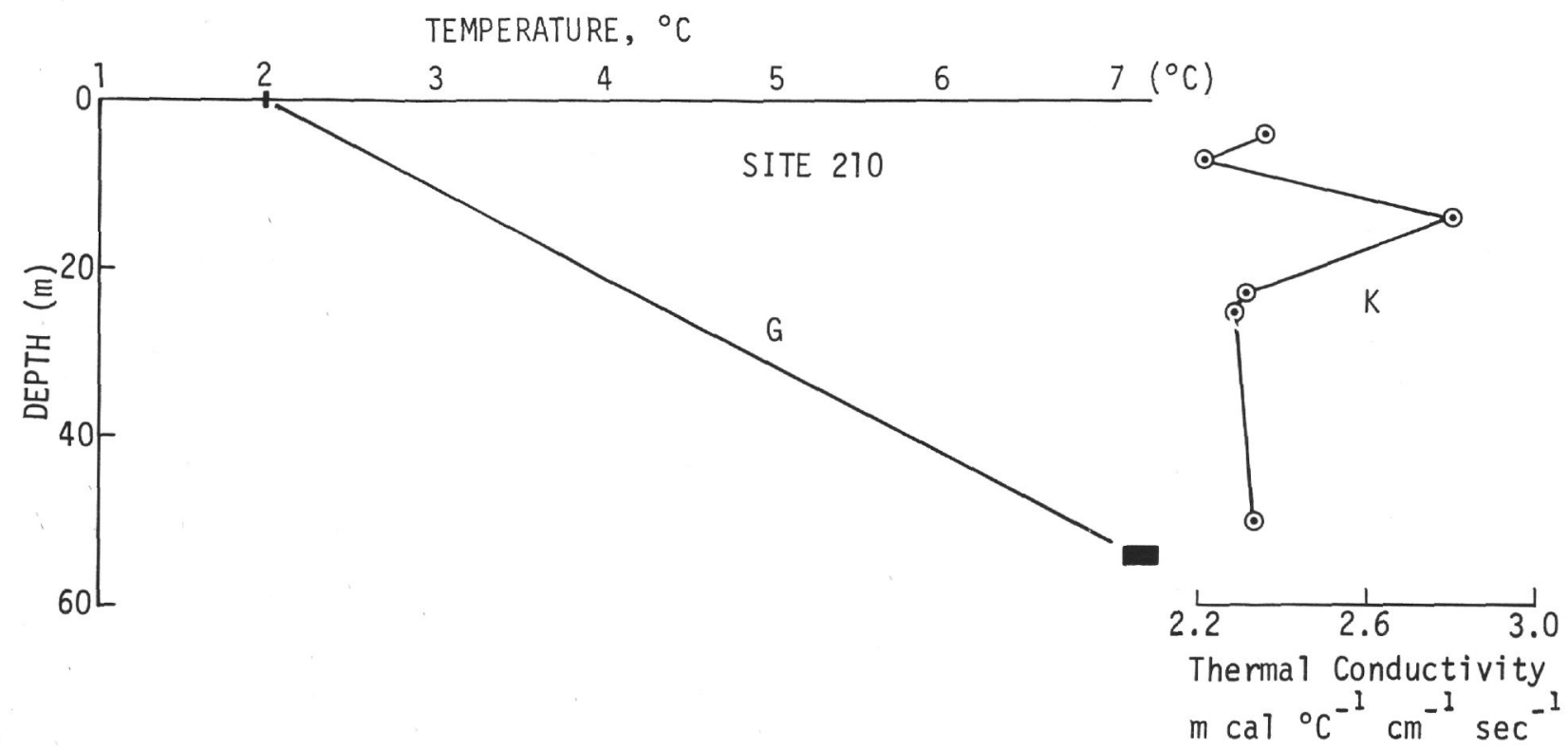

Figure 12. (a) Temperature, temperature gradient $(G)$, and thermal conductivity (K) versus depth at Site 209. Symbols same as for Figure 10. (b) Site 210. 


\section{Bottom Water Temperature Change}

A simple explanation of the temperature versus depth profile at Site 206 is a relatively recent change in bottom water temperature which is conducted downward as a temperature "wave". For example, the dashed curve of Figure 11 results from a step change in bottom water temperature 200 years ago of $-5.0^{\circ} \mathrm{C}$, imposed on sediments with a bottom water temperature of $7.0^{\circ} \mathrm{C}$ and an equilibrium temperature gradient of $1.5 \times 10^{-3^{\circ}} \mathrm{C} / \mathrm{cm}$, as determined from the measured temperatures at 174 and 304 meters. Calculations are taken from the conduction formulas of Carslaw and Jaeger (1959, p. 63). The assumption of uniform thermal diffusivity with depth seems justified from the relatively small change of thermal conductivity with depth. The calculated curve differs from the measured temperatures by less than $0.5^{\circ} \mathrm{C}$ everywhere. Of course, a closer fit could be obtained from a more complicated thermal history; however, the present data do not justify additional assumptions.

Although the measured values can be reasonably matched with such a bottom water temperature change, we need to evaluate the possible geological or oceanographic changes which might have caused it. Kennett et al. (1972) discuss possible changes in the arrangement of land masses, and hence of current systems, as a result of sea floor spreading during the Tertiary between Australia and Antarctica. The implications of this work for bottom water temperatures in this region are not obvious, and the geological processes are much too far removed in the past to have caused the temperature profile at Site 206. Deep water temperatures in the oceans are stabilized by the renewal of water which sinks after cooling or in association with the freezing of ice at higher latitudes. The rate of formation of those deep waters might be expected to vary with climate, but there is not evidence to suggest that it had ceased before $200 \mathrm{yrs}$ B.P. so as to cause much warmer bottom temperatures. In fact, the evidence of relatively uniform bottom water temperatures throughout the Pacific (Wooster and Volkmann, 1960) and the time constant of hundreds to thousands of years for lateral advection of these waters (Broecker, 1963) require that the process has remained relatively constant over this period, at least.

Thus, there is no obvious explanation for the large change in gradient with depth observed at Site 206. Due to uncertainties in measurement techniques associated with this new method, we must refrain from assuming regional or worldwide implications until additional detailed measurements are obtained at other deep drilling sites. With the available data, the safest assumption is that the heat flow at Site 206 is best represented by the temperatures measured to 143 meters depth (Table 1).

\section{COMPARISON WITH MARINE HEAT FLOW DATA}

One of the objectives of heat-flow measurement by Deep Sea Drilling Project is to compare results with the many values obtained by the standard oceanographic methods. From values which have only recently been published or are in press, it is seen that the heat flow of the Melanesian region is complex (Figure 13). In the following paragraphs, we make this comparison for each of the four Leg 21 sites at which measurements were successful.

Site 204. Seaward of the Tonga Trench, there are two nearby values at sites comparable to Site 204 (Sclater et al., 1972). Values of $1.84 \mathrm{HFU}$ and $1.16 \mathrm{HFU}$ were measured approximately $60 \mathrm{~km}$ to the southwest and $140 \mathrm{~km}$ to the northeast, respectively. Both of these values are significantly higher than that measured at Site 204. The values of $1.84 \mathrm{HFU}$ to the southwest may have a large error due to tilting of the oceanographic instrumentation. Although the age of the sea floor at Site 204 cannot be deduced from magnetic anomalies, the drilling results indicate that it is at least Cretaceous, perhaps older. The value of $0.8 \mathrm{HFU}$ measured at this site, and that of $1.16 \mathrm{HFU}$ to the northeast, are both within the range of heat flow expected for such old sea floor (Sclater and Francheteau, 1970).

Site 206. The oceanographic data to compare with the value measured at this site, in the New Caledonian Basin, are few and distant. Approximately $600 \mathrm{~km}$ to the north, a value of $1.3 \mathrm{HFU}$ was measured in the northward extension of the same basin, and several measurements to the east and southeast of that measurement give similarly "normal" values (Sclater et al., 1972). Several hundred kilometers to the southwest on the Lord Howe Rise, heat flow values appear about twice normal by the oceanographic method (Grim, 1969). Hence the value measured in the upper part of the hole at Site 206 (1.3-1.5 HFU) appears consistent with the oceanographic data to the north. The much lower values (0.3-0.5 HFU) deduced from the measurements below 143 meters are not, but additional data from DSDP sites will be required to assess the regional significance of this difference, if any.

Site 209. This site is located in relatively shallow water on the seaward edge of the Queensland Plateau. The nearest oceanographic measurements are a value of $1.48 \mathrm{HFU}$ about $200 \mathrm{~km}$ southwest on the same feature, and a value of $1.89 \mathrm{HFU}$ about $150 \mathrm{~km}$ east and northeast in the Coral Sea Basin (Langseth et al., 1971). The latter value is comparable to the average value of $2.0 \mathrm{HFU}$ at Site 209, and is within the error estimates for each depth interval. Only the western margin of the Queensland Plateau, near Australia, shows values $\geqslant 2.0 \mathrm{HFU}$ (Langseth et al., 1971).

Site 210. The oceanographic measurements nearest to this site in the Coral Sea Basin are about $100 \mathrm{~km}$ both east and west. The heat flow values are, respectively, $1.72 \mathrm{HFU}$ (Langseth et al., 1971, sta. 133) and 1.63 HFU (Halunen and Von Herzen, in press, sta. LSDH-50), both somewhat lower than that measured at Site 210. The higher heat flow at Site 210, and perhaps also at Site 209, might be explained in two ways. (First, a relatively recent (10-30 years ago) warming of bottom water temperatures such that the gradient between zero and 10 meters below bottom (penetration of oceanographic probe) may have been reduced proportionately more than that between zero and 50 meters. The amplitude of the temperature change required is of the order of a few tenths ${ }^{\circ} \mathrm{C}$. Second, a rapid sedimentation rate may have reduced the gradient upwards (Von Herzen and Uyeda, 1963). At Site 210, the sedimentation rate is high $\left(3-6 \mathrm{~cm} / 10^{3}\right.$ years $)$ and is presently at its maximum. To explain a significant difference between intervals 0 to 10 meters and 0 to 50 meters, however, would 


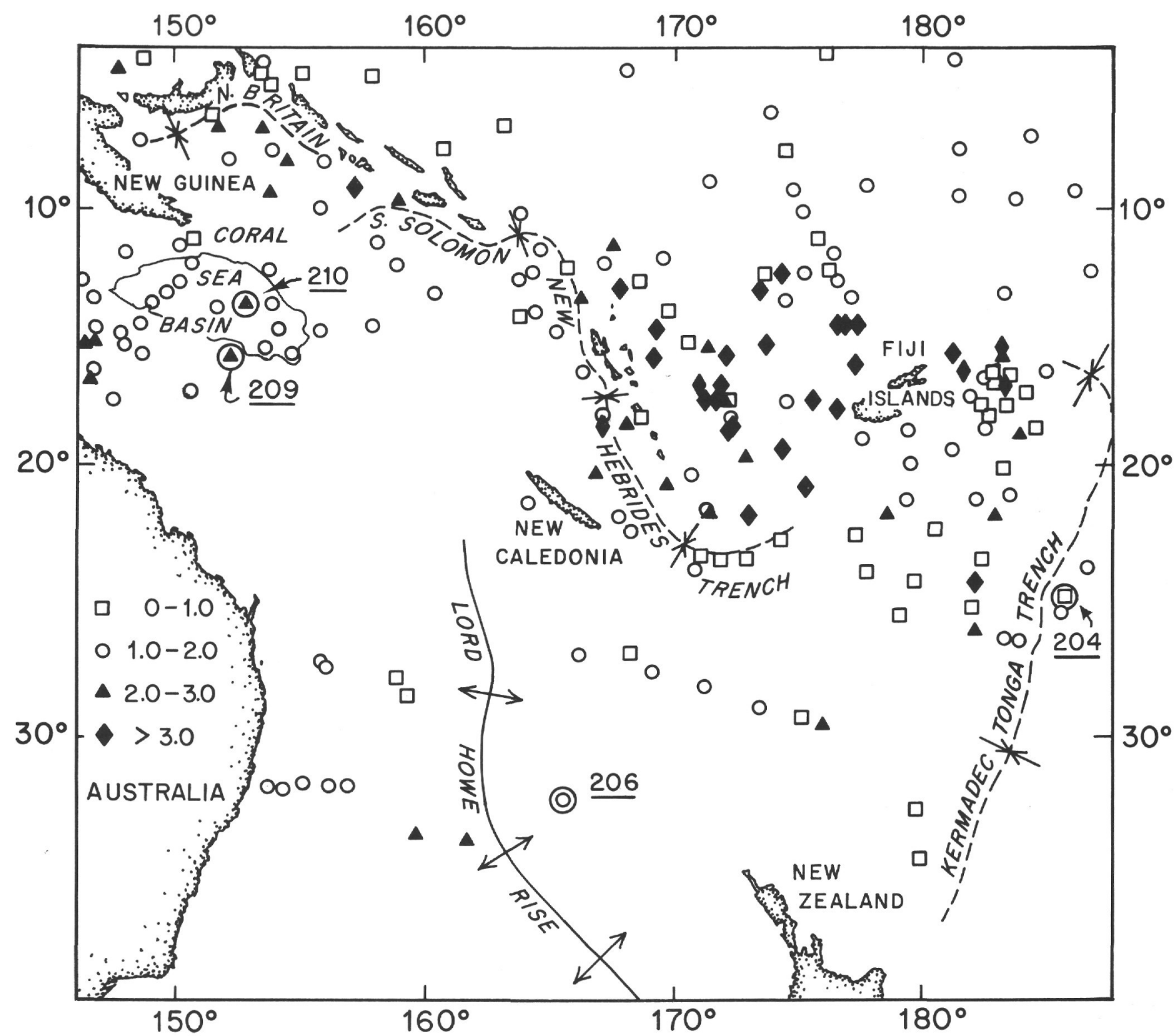

Figure 13. Heat flow values in the Melanesian area, SW Pacific. Values represented by symbols as given in the legend $\left(\mu \mathrm{cal} / \mathrm{cm}^{2} \mathrm{sec}=H F U\right) . \mathrm{Leg} 21$ sites denoted by larger circles around symbol.

require a very high sedimentation rate on the order of 100 $\mathrm{cm} / 10^{3} \mathrm{y}$ over the past 105 years or so. Presently there is little evidence to suggest either or both of these possibilities; more definitive conclusions will probably have to await more detailed measurements at future DSDP sites.

\section{ACKNOWLEDGMENTS}

Mr. Jay Hess assisted in the measurements and maintenance of instrumentation at sea. Most thermal conductivity measurements were carried out by the competent technicians of the DSDP. Valuable assistance was provided throughout by the ship and drilling crew of the D/V Glomar Challenger. I am grateful to the Co-Chief Scientists of Leg 21, Drs. R. Burns and J. Andrews, for the opportunity to make these measurements, and to Dr. J. Sclater for helpful comments.
Financial support for this program was provided by the National Science Foundation under grant GA 28504 and through the Deep Sea Drilling Project.

\section{REFERENCES}

Broecker, W., 1963. Radioisotopes and large-scale oceanic mixing. In The Sea, vol. 2. M. N. Hill (Ed.). New York (Wiley Interscience) 88 .

Bullard, E. C., Maxwell, A. E., and Revelle, R., 1956. Heat flow through the deep sea floor. Advances in Geophysics. v. 3. 153.

Burns, R. E., 1970. Heat flow operations at holes 35.0 and 35.1. In McManus, D. A., Burns, R. E. et al., 1970. Initial Reports of the Deep Sea Drilling Project, Volume V. Washington (U.S. Government Printing Office).

Carslaw, H. S. and Jaeger, J. C., 1959. Conduction of Heat in Solids, Oxford (Clarendon Press) [2nd ed.] . 510. 


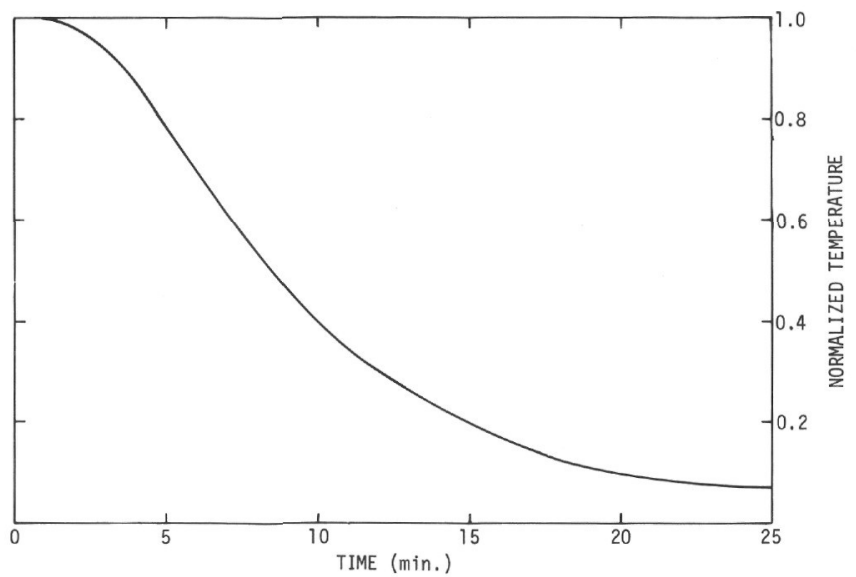

Figure 14. Temperature decay at center of a circular cylinder 2.5 inches in diameter, initially at temperature $T=1$, and $T=0$ on circumference after $t=0$. Thermal diffusivity assumed $4 \times 10^{-3} \mathrm{~cm}^{2} / \mathrm{sec}$ (Carslaw and Jaeger, 1959, fig. 12).

Clark, S. P., Jr., 1966. Handbook of Physical Constants. Geol. Soc. of Am. Mem. 97. 587.

Erickson, A., 1973. Initial Report on down-hole temperature and shipboard thermal conductivity measurements on Leg 19 of DSDP. In Creager, J. S., Scholl, D. W., et al., 1973, Initial Reports of the Deep Sea Drilling, Project, Volume 19, Washington (U.S. Government Printing Office) p. 643-656.

Grim, P. J., 1969. Heat flow measurements in the Tasman Sea. J. Geophys. Res. 74, 3933.

Halunen, A. J., Jr., and Von Herzen, R. P., in press. Heat flow in the western equatorial Pacific Ocean. J. Geophys. Res.

Hamilton, E. L., 1964. Consolidation characteristics and related properties of sediments from experimental Mohole (Guadalupe Site). J. Geophys. Res. 69, 4257.

Kennett, J. P., Burns, R .E., Andrews, J. E., Churkin, M., Davies, T. A. Dumitrica, P., Edwards, A. R., Galehouse, J. S., Packham, G. H., and van der Lingen, G. J., 1972. Australian-Antarctic Continental drift, paleocirculation changes and Oligocene deep-sea erosion. Nature Phys. Sci. 239, 51.
Langseth, M. G., Jr., Le Pichon, X., and Ewing, M., 1966. Crustal structure of the mid-ocean ridges, 5. Heat flow through the Atlantic Ocean floor and convection currents. J. Geophys. Res. 71, 5321.

Langseth, M. G., Jr., Malone, I., and Breger, D., 1971. Sea floor geothermal measurements from VEMA Cruise 24. Tech. Rep. No. 3-CU-3-71, Lamont-Doherty Geological Observatory. $452 \mathrm{p}$.

Lapwood, E .R., 1948. Convection of a fluid in a porous medium. Proc. Cambridge Phil. Soc. 44, 508.

Lee, W. H. K., 1970 . On the global variations of terrestrial heat-flow. Phys. Earth Planet. Interiors. 2, 332.

Lister, C .R .B., 1972. On the thermal balance of a mid-ocean ridge. Geophys. J. R. Astr. Soc. 26, 515.

Lubimova, E. A., Von Herzen, R. P., and Udintsev, G., 1965. On heat transfer through the ocean floor. In Terrestrial Heat Flow. W. H. K. Lee (Ed.). Geophysical Monographs 8, Am. Geophys. Union. 78.

Ratcliffe, E. H., 1960. The thermal conductivities of ocean sediments. J. Geophys. Res. 65 (5), 1535.

Sclater, J. G., and Francheteau, J., 1970. The implications of terrestrial heat flow observations on current tectonic and geochemical models of the crust and upper mantle of the earth. Geophys. J. R. Astr. Soc. 20, 509.

Sclater, J. G., Ritter, U. G., and Dixon, F. S., 1972. Heat flow in the southwestern Pacific. J. Geophys. Res. 77, 5697.

Von Herzen, R. P., and Uyeda, S., 1963. Heat flow through the eastern Pacific Ocean floor. J. Geophy. Res. 68, 4219.

Von Herzen, R. P., Fiske, R. J., and Sutton, G., 1971. Geothermal measurements on Leg 8. In Tracey, J. I., Jr., Sutton, G. H. et al., 1971. Initial Reports of the Deep Sea Drilling Project, Volume VIII. Washington (U.S. Government Printing Office). 837.

Wooster, W. S., and Volkmann, G. H., Indications of deep Pacific circulation from distribution of properties at five kilometers. J. Geophys. Res. 65, 1239.

\section{APPENDIX}

The temperature at the center of a cylindrical region, after a temperature change has been imposed on its outer boundary, is given by Carslaw and Jaeger (1959), p. 199, fig. 12). The the case where a core is contained within the inner barrel, we take the diameter as 2.5 inches $(6.3 \mathrm{~cm})$ and the diffu sivity of sediments as 4 $\times 10^{-3} \mathrm{~cm}^{2} / \mathrm{sec}$. Figure 14 shows the approach to temperature equilibrium on the axis of the cylindrical region. The temperaturemeasuring probe and instrument within the core barrel will not significantly affect the approach to equilibrium as measured at the probe. 